\title{
Correction to: Numerical Simulation and Experimental Validation of Nondendritic Structure Formation in Magnesium Alloy Under Oscillation and Ultrasonic Vibration
}

\author{
ANSHAN YU, XIANGJIE YANG, HONGMIN GUO, KUN YU, XIUYUAN SUN, \\ and ZIXIN LI
}

https://doi.org/10.1007/s11663-019-01694-x

(C) The Minerals, Metals \& Materials Society and ASM International 2019

\section{Correction to: Metallurgical and Materials Transactions B https://doi.org/10.1007/s11663-019-01654-5}

THE equation 1 " $1-\phi$ " should be " $1-\phi^{2}$ ".

The equation 2 last " $\partial \mathrm{u} / \partial \mathrm{t}$ " should be " $\partial \phi / \partial t$ " .

The corrected equations are

$$
\begin{aligned}
\tau(\boldsymbol{n}) & {[1+(1-k) u] \frac{\partial \varphi^{2}}{\partial t} } \\
= & \varphi\left(1-\varphi^{2}\right)-\lambda\left(1-\varphi^{2}\right)^{2}\left(u+\theta_{\mathrm{sys}}\right)+\nabla \cdot\left\{[W(\boldsymbol{n})]^{2} \nabla \varphi\right\} \\
& -\frac{\partial}{\partial x}\left[W(\boldsymbol{n}) W^{\prime}(\boldsymbol{n}) \frac{\partial \varphi}{\partial y}\right]+\frac{\partial}{\partial y}\left[W(\boldsymbol{n}) W^{\prime}(\boldsymbol{n}) \frac{\partial \varphi}{\partial x}\right]
\end{aligned}
$$

$$
\begin{aligned}
& \left(\frac{1+k}{2}-\frac{1-k}{2} \varphi\right)\left(\frac{\partial u}{\partial t}+U \cdot \nabla u\right) \\
& \quad=\nabla\left(D \frac{1-\varphi}{2} \nabla u+J_{A T}\right)+\frac{1}{2} \frac{\partial \varphi}{\partial t}[1+(1-k) u]
\end{aligned}
$$

The caption of Figure 21 should say, "Microstructure of solidified AZ91D at a fixed oscillation frequency (1 $\mathrm{Hz})$, ultrasonic power $(1000 \mathrm{~W})$, and oscillation amplitude $(4 \pi / 3)$ for inclined angles of $(a) 25 \mathrm{deg}$, (b) $20 \mathrm{deg}$, and (c) $15 \mathrm{deg}$.

Publisher's Note Springer Nature remains neutral with regard to jurisdictional claims in published maps and institutional affiliations.

ANSHAN YU, XIANGJIE YANG, KUN YU, XIUYUAN SUN, and ZIXIN LI are with the School of Mechanical and Electrical Engineering, Nanchang University, Nanchang 330031, P.R. China and also with the Key Laboratory of Near Net Forming in Jiangxi Province, Nanchang 330031, P.R. China. Contact e-mail: yangxj@ncu.edu.cn HONGMIN GUO is with the Key Laboratory of Near Net Forming in Jiangxi Province and also with the Department of Materials Science and Engineering, Nanchang University, Nanchang 330031, P.R. China.

The original article can be found online at https://doi.org/10.1007/ s11663-019-01654-5.

Article published online September 30, 2019. 